\title{
Neoseiulus tunus (De Leon, 1967) (Acari: Phytoseiidae): is this a potential natural enemy of Aculops lycopersici (Massee, 1937) (Acari: Eriophyidae)?
}

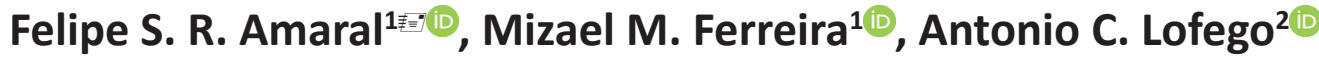 \\ ${ }^{1}$ Programa de Pós-Graduação em Biodiversidade, Universidade Estadual Paulista (UNESP), São José do Rio Preto, SP, Brazil. \\ ${ }^{2}$ Departamento de Biociências, Universidade Estadual Paulista (UNESP), São José do Rio Preto, SP, Brazil. \\ 麦=-Corresponding author: felipe.amaral@unesp.br
}

Edited by: Maria F. G. V. Penãflor

Received: June 18, 2021. Accepted: October 25, 2021. Published: November 29, 2021.

Abstract. This study aimed to determine the biological parameters of Neoseiulus tunus (De Leon, 1967) feeding on Aculops lycopersici (Massee, 1937). We conducted experiments to assess the predation rate of the former and its biological cycle when consuming $A$. lycopersici exclusively. Moreover, we assessed the preference of $N$. tunus for $A$. lycopersici concerning the pollen of Typha domingensis Pers. (Typhaceae) and Tetranychus urticae Koch, 1835, using free-choice tests. The obtained data indicates $A$. lycopersici is an appropriate prey to N. tunus, as it allows it to complete its development, reproduce and increase its population. We also noticed that this phytoseiid prefers $A$. lycopersici to the two other food sources. Though more robust studies will be needed, these preliminary results allow some inferences, such as $N$. tunus being a potential natural enemy of A. lycopersici.

Keywords: tomato russet mite, biological control, predation, life table, free-choice feeding.

The tomato russet mite, Aculops lycopersici (Massee, 1937) (Eriophyidae), has been recorded as a pest attacking several solanaceous plants in different parts of the world (EPPO 2018). Among them, it attacks tomato plants (Solanum lycopersicum L., Solanaceae), having the potential to bring huge losses to farmers (Duso et al. 2010). Acaricides as chemical control of $A$. lycopersici is difficult, and often inefficient (Vervaet et al. 2021). Furthermore, the use of pesticides is potentially harmful to human health and also to the environment (Lai 2017; Larsen et al. 2017). For these reasons, the need for alternative methods to control the populations of this eriophyid is indisputable and one possibility is biological control.

To date, compared to other tomato pests, few studies have searched for natural enemies of $A$. lycopersici. Among them, studies using predacious mites, especially those belonging to the Phytoseiidae Berlese, 1916, have reached the most promising results (Vervaet et al. 2021). Though there are a few candidates to act as its controllers, investigations of native natural enemies are necessary.

Neoseiulus tunus (De Leon, 1967) is a species frequently recorded in the Neotropics (Cavalcante et al. 2017). It may use solanaceous plants as hosts, being one of the most frequent phytoseiids on these plants (Tixier et al. 2020). Furtado et al. (2016) registered N. tunus as the most abundant Amblyseiinae (Phytoseiidae) species in Solanaceae collected in Southeast Brazil. Even though it is a common species, few biological studies have dealt with this species. Moreover, these few were restricted to its diet evaluation and reproductive strategy (Cavalcante et al. 2015; 2017). Therefore, considering the frequency in which $N$. tunus is found on solanaceous plants and the fact that many species of the family Phytoseiidae are efficient predators of agricultural pests, $N$. tunus may be a potential natural enemy of Solanaceae pests such as $A$. lycopersici. For this reason, we conducted three experiments designed to evaluate this hypothesis. The first experiment consisted of a biological essay intended to determine the life table of $N$. tunus when fed with $A$. lycopersici. The second experiment involved a predation test aimed at determining the predation potential of $N$. tunus on this same prey. Lastly, the third experiment had the aim of determining the feeding preference of this predator concerning three different food items, including the target pest $A$. lycopersici.

All three experiments used specimens of $N$. tunus kept in rearing units, according to McMurtry \& Scriven (1964). The specimens of the initial population were obtained in a forest fragment. They were collected on leaves of Trichilia casaretti C. Dc (Meliaceae) in the municipality of Icém, São Paulo state, Brazil. After being established, the predators colonies were kept in an acclimatized greenhouse (B.O.D.) at $25 \pm 1^{\circ} \mathrm{C}$, relative humidity of $70 \pm 10 \%$, and a 12 -hour photoperiod. All females were fed with southern cattail pollen (Typha domingensis Pers., Typhaceae), A. lycopersici, and Tetranychus urticae Koch, 1836 (Acari: Tetranychidae). The mites that were used as food-T. urticae and A. lycopersici-were reared in jack bean plants [Canavalia ensiformis (L.) DC., Fabaceae] and tomato plants (S. lycopersicum), respectively.

The biological essay of $N$. tunus began with 25 experimental units, each consisting of an acrylic container $(1.5 \mathrm{~cm}$ in height; $2.5 \mathrm{~cm}$ in diameter) containing carrageenan $(5 \mathrm{mg} / 250 \mathrm{~mL}$ of water). We placed a disk (with $2 \mathrm{~cm}$ in diameter) of a tomato leaflet over the carrageenan, with the abaxial surface facing up. The margins of the container were covered with entomological glue to obstruct the passage, preventing both an escape of the mites and an invasion from other organisms. To each unit, we offered all mobile stages of $A$. lycopersici as sustenance. The food was replaced daily. To begin the experiment, each experimental unit received an adult female that came from the rearing colonies. After 24 hours, these females were removed from the containers along with their exceeding eggs, in such a way that only one egg remained in each unit. During the immature stages, each unit was examined three times per day (at 7 AM, 3 PM, and 11 PM). After the emergence of the adults, we examined all units every 24 hours for counting and the removal of the eggs laid by the predators. Mites found dead on the glue were not considered for the analyses. The life table was built according to the method proposed by Maia \& Luiz (2006), using the program SAS University Edition.

To evaluate the predation potential, 15 females of $N$. tunus were separated from the rearing colonies and transferred to an arena with 
no food, where they were kept for eight hours. After that, the females were separated into individual experimental units as described above. Then, we added 50 specimens of $A$. lycopersici in each unit. After 24 hours, we counted the number of $A$. lycopersici still present in the experimental unit to determine the amount of prey consumed during this period.

To investigate food preference, we conducted double-choice tests with ten repetitions per treatment. Each repetition consisted of two disks of tomato leaflets ( $3 \mathrm{~cm}$ in diameter) placed side by side on a wet foam lying on a plastic container (Fig. 1). A fragment of tomato leaf measuring $1.5 \mathrm{~cm} \times 1 \mathrm{~cm}$ was placed between the disks, to function as a bridge to predatory mites. We placed a fragment of a coverslip over each disk, resting on cotton fibers, making a shelter that could aid in the containment of phytoseiids. At the center of this "bridge", we fixed a pin to assist in the release of predators. In a disk, we added specimens of the target prey A. lycopersici, and in a second disk, we added southern cattail pollen, spread throughout the disk, or T. urticae. The amount of prey added per disk was determined according to the number of phytophagous mites in naturally infested leaves. This number was around 90 specimens of $A$. lycopersici and 40 specimens of T. urticae per replicate, which were enough to guarantee there would still be prey on the disk by the end of the experiment. Ten females of $N$. tunus were released on the pinhead so they could descend and choose their food. Preference was determined after an analysis of the number of prey individuals on each disk. These were quantified after $1 \mathrm{~h}, 2 \mathrm{~h}, 4 \mathrm{~h}, 8 \mathrm{~h}$, and $24 \mathrm{~h}$. We also observed whether the prey was in their respective disks. Dead prey on the pin or the "bridge" leaf was not considered in the analyses. The difference between the number of mites observed in both disks was analyzed through generalized linear mixed models (GLMM) with Poisson's distribution using the R package "glmmTMB". "Time" was considered a random factor, and "Food" was treated as a fixed factor. For the evaluation of the difference between each time interval, we used R's "emmeans" package.

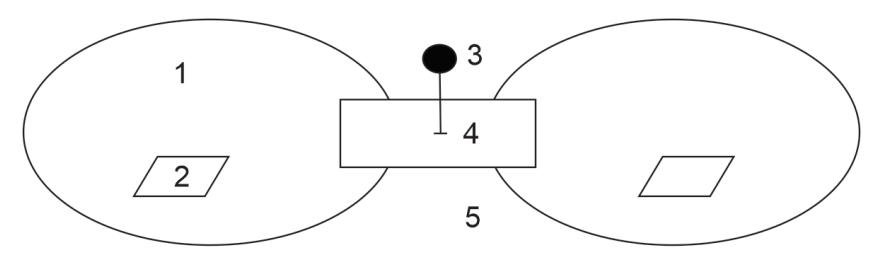

Figure 1. The experimental model of the food preference test. 1) disk of the leaflet of tomato with the abaxial surface facing up; 2) shelter composed of a fragment of coverslip on cotton fibers; 3) pin; 4) "bridge" made of a tomato leaflet fragment; 5) nylon foam.

With $A$. lycopersici as the exclusive food item, the predatory mite finished its development and reproduced, resulting in parameters that show population growth (Tab. 1). All individuals reached the adult stage, and all were females.

This is the first study to test $A$. lycopersici as a viable food item for $N$. tunus. It is also the first study to evaluate the whole biological cycle of this predator, providing more robust information on its biological features. In previous studies, Cavalcante et al. $(2015 ; 2017)$ only assessed the oviposition/predation rates and the reproductive strategy of this predator when fed with eggs of Bemisia tabaci (Gennadius, 1889) (Hemiptera: Aleyrodidae) and T. urticae, as well as larvae/protonymphs of Aleuroglyphus ovatus (Tropeau, 1879) (Acari: Acaridae). Some species of the genus Neoseiulus Hughes, 1948 are potentially useful to the control of $A$. lycopersici. Lineages of Neoseiulus californicus (McGregor, 1954) previously fed with T. urticae and pollen have shown an intrinsic growth rate $\left(r_{m}\right)$ of 0.172 and 0.205 respectively, consuming $A$. lycopersci (Castagnoli et al. 2003). With this same prey, Neoseiulus cucumeris (Oudemans, 1930) presented an $r_{m}=$ 0.211 (Al-Azzazy et al. 2018). Even though these values are still slightly higher than those found for $N$. tunus in this study $\left(r_{m}=0.159\right)$, it is necessary to consider the predation potential as an important factor in the search for an effective natural enemy. We found out that $N$. tunus, consumed $24.4 \pm 2.8$ prey/female in 24 hours, an average similar to the one obtained by Castagnoli et al. (2003) for N. cucumeris (23.89 prey/ female) and almost double the average found by Al-Azzazy et al. (2018) for N. californicus (12.89 prey/female) with the same prey.

Table 1. Populational parameters of Neoseiulus tunus feeding on Aculops lycopersici.

\begin{tabular}{lcc}
\hline Parameters & $\mathbf{N}$ & Mean \pm SE \\
\hline Egg (days) & 25 & $1.8 \pm 0.12$ \\
Larva (days) & 25 & $1 \pm 0.04$ \\
\hline Protonymph (days) & 22 & $1.5 \pm 0.07$ \\
\hline Deutonymph (days) & 19 & $1.7 \pm 0.07$ \\
\hline Egg-adult (days) & 17 & $6 \pm 0.14$ \\
\hline Pre-oviposition (days) & 13 & $3.6 \pm 0.18$ \\
\hline Oviposition (days) & 13 & $13.15 \pm 1.6$ \\
Post-oviposition (days) & 13 & $1.69 \pm 0.26$ \\
\hline Longevity (days) & 13 & $16.85 \pm 1.72$ \\
\hline Fecundity (eggs/female) & 13 & $13.07 \pm 1.54$ \\
\hline Daily oviposition (eggs/female/day) & 13 & $1.06 \pm 0.09$ \\
$R_{0}$ & 13 & $7.61 \pm 3.175$ \\
\hline$r_{m}$ & 13 & $0.159 \pm 0.027$ \\
$\lambda$ & 13 & $1.172 \pm 0.032$ \\
\hline$D T$ & 13 & $12.91 \pm 1.32$ \\
\hline$R_{0}$ & 13 & $4.34 \pm 0.74$ \\
\hline
\end{tabular}

$R_{0}=$ net reproductive rate, $r=$ intrinsic rate of growth, $\lambda=$ finite growth rate, $T$ = average generation time, $D T=$ population doubling time. Sex ratio $=1$

In the food preference tests, most specimens of $N$. tunus chose the disk containing $A$. lycopersici over the one containing southern cattail pollen. This happened in all the time periods assessed (Fig. 2). Considering both $A$. lycopersici and $T$. urticae, a significantly larger number of phytoseiids was observed on the disk containing $A$. lycopersici, starting from the second hour of the experiment (Fig. 3). The choice of $N$. tunus for A. lycopersici over T. urticae and pollen, two other possible food sources found in tomato crops, suggests a preference of the predator for the target pest. Nonetheless, other food sources should be tested in the future to corroborate this information, given that many other possible food items available for phytoseiids are available in tomato crops, such as other phytophagous mites, thrips, whiteflies, aphid honeydew, etc.

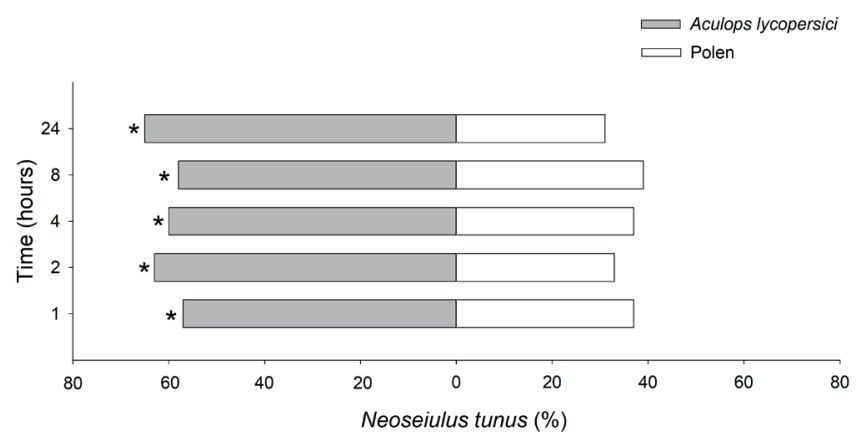

Figure 2. Frequency of Neoseiulus tunus in disks containing Aculops lycopersici and southern cattail pollen in different periods. Significant differences $(P<0.05)$

One of the determining factors in the success of the use of phytoseiids in biological control programs in tomato plants is their adaptability to their trichomes. These structures protect the plant against phytophagous mites (Sato 2011), but they can also interfere in the locomotion and development of phytoseiids, reducing their predation efficiency (Schimidt 2014). Some of the morphological features present in $N$. tunus, such as short and serrate setae and a narrow idiosoma, apparently guarantee better maneuverability among the trichomes (Duso 1992; Kreiter et al. 2003; McMurtry et al. 2013).

Thelytokous parthenogenesis-offspring composed only by femalesas a reproductive strategy in $N$. tunus had already been reported by Cavalcante et al. (2017) and was corroborated in this study. It is a 
relevant characteristic of this species in practical terms. The lack of need for a sexual partner makes massive rearing in lab conditions easier, as well as experiments on its life cycle. There is some evidence in the literature showing that females of phytoseiids consume more prey than males (Abdahlla et al. 2001; Gotoh et al. 2006; Li \& Zhang 2016), which suggests that all-female populations could consume higher quantities of prey when compared to sexually diverse populations. Another advantage of parthenogenetic populations for biological control is the preservation of natural or artificial pre-selected traits (such as tolerance to temperature and pesticides), given that there is no mating with native individuals, which diminishes the mite's genetic variability (Hoy \& Cave 1986; Cavalcante et al. 2017). On the other hand, parthenogenetic populations could bring disadvantages in the long term, such as the accumulation of deleterious mutations (Norton \& Palmer 1991).

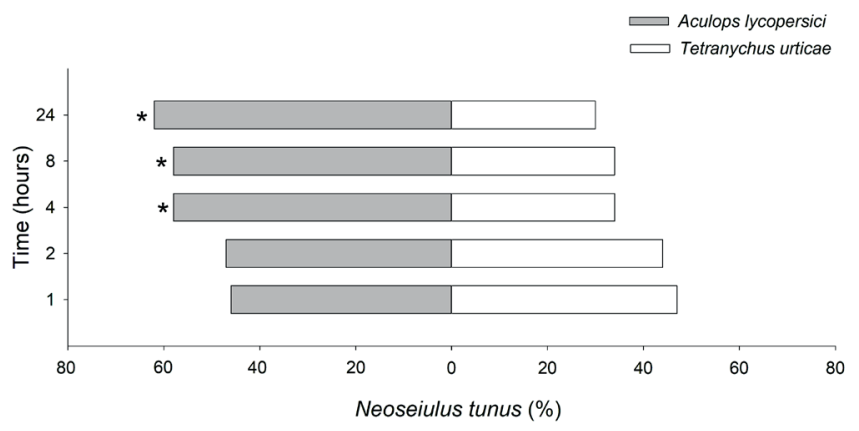

Figure 3. Frequency of Neoseiulus tunus in disks containing Aculops lycopersici and Tetranychus urticae in different periods. Significant differences $(P<0.05)$.

Though the biological control of $A$. lycopersici already counts with some promising species, for example $N$. californicus and $N$. cucumeris, the search for enemies that occur naturally in the same region of the pest is all-important. First, because it avoids the introduction of exotic species which could cause disequilibrium in the already established ecological relations. Second, because native species are already acclimatized to the region's environmental conditions. This is critical because a successful biological control depends, to a large extent, on external conditions that can affect the efficiency of the predator, such as temperature, humidity, type of host, and interspecific interactions like competition and predation. Considering all of this and also its geographical distribution (Demite et al. 2021), its occurrence in several species of solanaceous plants including tomatoes (Furtado et al. 2006; Tixier et al. 2020) plus the biological evidence presented in this study, $N$. tunus has the potential of being a natural neotropical enemy of $A$. lycopersici in tomato crops. However, we encourage more studies, specifically in greenhouses and/or in open fields, to assess the efficacy of this predatory mite in the populational control of $A$. lycopersici directly on the plants.

\section{Acknowledgments}

The authors are thankful to Fundação de Amparo à Pesquisa do Estado de São Paulo (FAPESP) for funding this work (process number 2013/05872-6). We also thank Dr. Rodolfo Mei Pelinson for his contribution on statistical analysis. $\mathrm{ACL}$ received a research productivity fellowship from CNPq (Proc. no. 310617/2018-9).

\section{Authors' contributions}

The text has been revised and approved by all authors. The experiments were conducted by FSRA and MMF, under the supervision of ACL. The analyses were made by FSRA.

\section{References}

Abdallah, A. A.; Zhang, Z. Q.; Masters, G. J.; Mcneill, S. (2001) Euseius finlandicus (Acari: Phytoseiidae) as a potential biocontrol agent against Tetranychus urticae (Acari: Tetranychidae): life history and feeding habits on three different types of food. Experimental and Applied. Acarology, 25(10): 833-847.

Al-Azzazy, M. M.; Al-Rehiayani, S. M.; Abdel-Baky, N. F. (2018) Life tables of the predatory mite Neoseiulus cucumeris (Acari: Phytoseiidae) on two pest mites as prey, Aculops lycopersici and Tetranychus urticae. Archives of Phytopathology and Plant Protection, 51(1112): 637-648. doi: 10.1080/03235408.2018.1507013

Castagnoli, M.; Simoni, S.; Liguori, M. (2003) Evaluation of Neoseiulus californicus (McGregor) (Acari: Phytoseiidae) as a candidate for the control of Aculops lycopersici (Tyron) (Acari Eriophyoidea): a preliminary study. Redia, 86: 97-100.

Cavalcante, A. C. C.; Dos Santos, V. L. V.; Rossi, L. C.; Moraes, G. J. de (2015) Potential of five Brazilian populations of Phytoseiidae (Acari) for the biological control of Bemisia tabaci (Insecta: Hemiptera). Journal of Economic entomology, 108(1): 29-33. doi: 10.1093/jee/ tou003

Cavalcante, A. C.; Demite, P. R.; Amaral, F. S.; Lofego, A. C.; Moraes, G. J. de (2017) Complementary description of Neoseiulus tunus (De Leon) (Acari: Mesostigmata: Phytoseiidae) and observation on its reproductive strategy. Acarologia, 57(3): 591-599. doi: 10.24349/ acarologia/20174178

Demite, P. R.; Moraes, G. J.; McMurtry, J. A.; Denmark, H. A.; Castilho, R. C. (2021) Phytoseiidae Database. www.lea.esalq.usp.br/ phytoseiidae. Access on: 02.vi.2021.

Duso, C. (1992) Role of Amblyseius aberrans (Oud.), Typhlodromus pyri (Scheuten) and Amblyseius andersoni (Chant) (Acari, Phytoseiidae) in vineyards: III. Influence of variety characteristics on the success of $A$. aberrans and T. pyri releases. Journal of Applied Entomology, 114(1-5): 455-462. doi: 10.1111/j.1439-0418.1992.tb01151.x

Duso, C.; Castagnoli, M.; Simoni, S.; Angeli, G. (2010) The impact of eriophyoids on crops: recent issues on Aculus schlechtendali, Calepitrimerus vitis and Aculops lycopersici. Experimental and Applied Acarology, 51: 151-168. doi: 10.1007/s10493-009-9300-0

European and Mediterranean Plant Protection Organization (EPPO) (2018) Aculops lycopersici distribution. https://gd.eppo.int/taxon/ VASALY/distribution. Access on: 02.vi.2021.

Furtado, I. P.; Moraes, G. J.; Kreiter, S.; Knapp, M. (2006) Search for effective natural enemies of Tetranychus evansi in south and southeast Brazil. Experimental and Applied Acarology, 40(3): 157174. doi: 10.1007/s10493-006-9045-y

Gotoh, T.; Tsuchiya, A.; Kitashima, Y. (2006) Influence of prey on developmental performance, reproduction and prey consumption of Neoseiulus californicus (Acari: Phytoseiidae). Experimental and Applied Acarology, 40(3): 189-204. doi: 10.1007/s10493-006-90323

Hoy, M. A.; Cave, F. E. (1986) Screening for thelytoky in the parahaploid phytoseiid Metaseiulus occidentalis (Nesbitt). Experimental and Applied Acarology, 2(3): 273-276. doi: 10.1007/BF01193959

Kreiter, S.; Tixier, M. S.; Bourgeois, T. (2003) Do generalist phytoseiid mites (Gamasida: Phytoseiidae) have interactions with their host plants? International Journal of Tropical Insect Science, 23(1): 3550. doi: $10.1017 / \mathrm{s} 1742758400012236$

Lai, W. (2017) Pesticide use and health outcomes: evidence from agricultural water pollution in China. Journal of environmental economics and management, 86: 93-120. doi: 10.1016/j. jeem.2017.05.006

Larsen, A. E.; Gaines, S. D.; Deschênes, O. (2017) Agricultural pesticide use and adverse birth outcomes in the San Joaquin Valley of California. Nature Communications, 8(1): 1-9. doi: 10.1038/s41467017-00349-2

Li, G. Y.; Zhang, Z. Q. (2016) Some factors affecting the development, survival and prey consumption of Neoseiulus cucumeris (Acari: Phytoseiidae) feeding on Tetranychus urticae eggs (Acari: Tetranychidae). Systematic and Applied Acarology, 21(5): 555-566. doi: 10.11158/saa.21.5.1

Maia, A. D. H. N.; Luiz, A. J. B. (2006) Programa SAS para análise de tabelas de vida e fertilidade de artrópodes: método Jackknife. Embrapa Meio Ambiente-Comunicado Técnico (INFOTECA-E).

McMurtry, J. A.; Scriven, G. T. (1964) Studies on the feeding, 
reproduction, and development of Amblyseius hibisci (Acarina: Phytoseiidae) on various food substances. Annals of the Entomological Society of America, 57(5): 649-655. doi: 10.1093/ aesa/57.5.649

McMurtry, J. A.; Moraes, G. J. de ; Sourassou, N. F. (2013) Revision of the lifestyles of phytoseiid mites (Acari: Phytoseiidae) and implications for biological control strategies. Systematic and Applied Acarology, 18(4): 297-320. doi: 10.11158/saa.18.4.1

Norton, R. A.; Palmer, S. C. (1991) The distribution, mechanisms and evolutionary significance of parthenogenesis in oribatid mites. In: Schuster, R.; Murphy P. W. (Eds), The Acari, pp. 107-136. Dordrecht: Springer.

Sato, M. M.; Moraes, G. J.; Haddad, M. L.; Wekesa, V. W. (2011) Effect of trichomes on the predation of Tetranychus urticae (Acari: Tetranychidae) by Phytoseiulus macropilis (Acari: Phytoseiidae) on tomato, and the interference of webbing. Experimental and Applied Acarology, 54(1): 21-32. doi: 10.1007/s10493-011-9426-8

Schmidt, R. A. (2014) Leaf structures affect predatory mites (Acari: Phytoseiidae) and biological control: a review. Experimental and Applied Acarology, 62(1): 1-17. doi: 10.1007/s10493-013-9730-6

Tixier, M.-S.; Douin, M.; Kreiter, S. (2020) Phytoseiidae (Acari: Mesostigmata) on plants of the family Solanaceae: results of a survey in the south of France and a review of world biodiversity. Experimental and Applied Acarology, 81(3): 357-388. doi: 10.1007/ s10493-020-00507-0

Van Leeuwen, T.; Witters, J.; Nauen, R.; Duso, C.; Tirry, L. (2010) The control of eriophyoid mites: state of the art and future challenges. Experimental and Applied Acarology, 51(1): 205-224. doi: 10.1007/ s10493-009-9312-9

Vervaet, L.; De Vis, R.; De Clercq, P.; Van Leeuwen; T. (2021) Is the emerging mite pest Aculops lycopersici controllable? Global and genome-based insights in its biology and management. Pest Management Science, 77(6): 2635-2644. doi: 10.1002/ps.6265 